\title{
Attitudes and Awareness Towards Cardiopulmonary Resuscitation Among Preparatory Year Students of Umm Al-Qura University
} Ahmed Ali Shammah $^{{ }^{*}}$, Ashraf Elbakh ${ }^{1}$, Mohamad Mohannad Jamal ${ }^{2}$, Ahmed Dakhiel Allah Althubyani ${ }^{2}$, Ziyad Mohammed Alotaibi $^{2}$, Mohammed Mudayni Alasmari ${ }^{2}$, Sharaf Mohammed Alharethi ${ }^{2}$ and Redha Abdullrazzaq Felemban ${ }^{2}$

${ }^{1}$ Department of Clinical Technology, Faculty of Applied Medical Science, EMS, Umm Al-Qura University, Saudi Arabia ${ }^{2}$ Emergency Medical Services Student, EMS, Umm Al-Qura University, Saudi Arabia

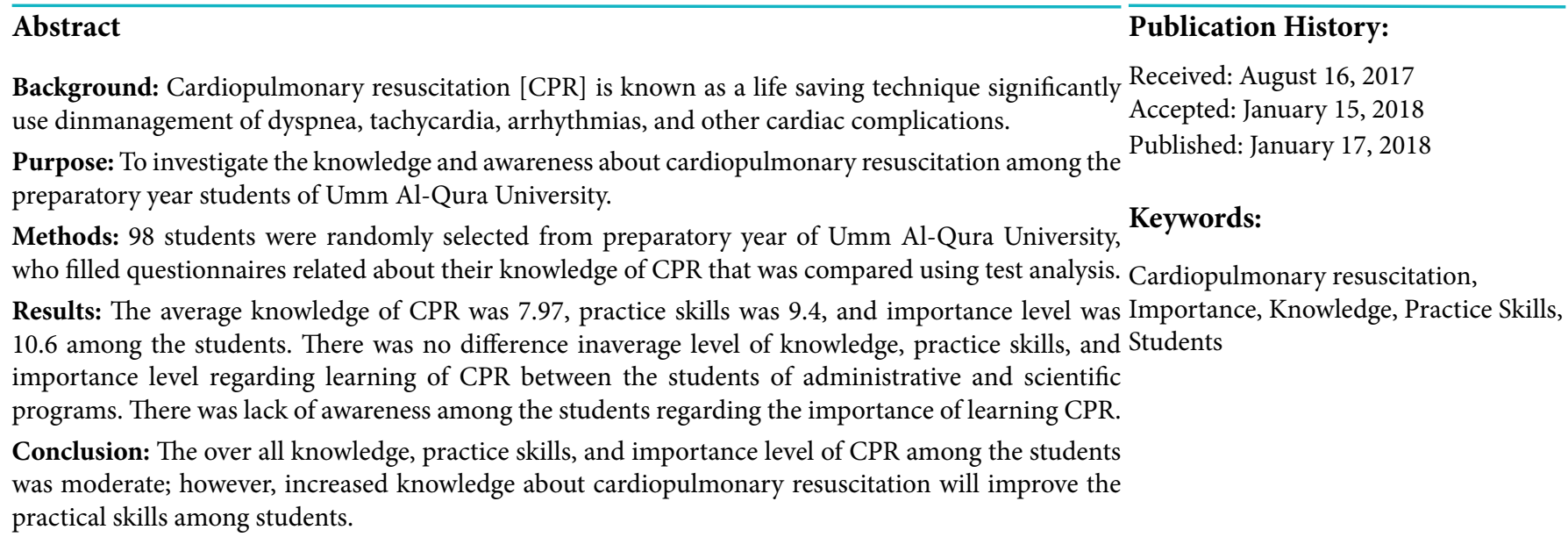

\section{Introduction}

Cardiopulmonary disease is recognized as ever emortalthreatto the Saudi population. For instance, around 25,000 people in Saudi Arabia face dmortal complications because of cardiopulmonary diseases. A significant number of techniques have been developed for providing quality of care to the patients [1]. Cardiopulmonary resuscitation $[\mathrm{CPR}]$ refers to a life saving technique that is significantly useful for managing dyspnea, tachycardia, arrhythmias and other cardiac complications. This technique utilizes the combination of chest compression, which is helpful for maintaining the flow of oxygen at blood to the brain and other vital organs [1]. Tragic and hazardous consequences can be occurred due to lack of inability and training to cope with medical emergencies. Previous studies have shown lack of knowledge regarding CPR $[2,3]$.

\section{Importance of cardiopulmonary resuscitation}

Cardiac arrestisthe leading cause of deaths world wide, although the emergency cardiaccare has greatly advanced. It is estimated that around $70 \%$ of cardiacar rest occurs within non-clinical environment; out of which, around $10 \%$ individual ssurvived besides the absence of rudimentary medical care [4]. Majority of patient suffering cardiac arrest usually face mortal complications because of unavailability of immediate CPR or lack of knowledge regarding this technique. $\mathrm{CPR}$ is known as a significant element of initial care for the victims suffering from cardiac arrest. The quality of CPR is directly associated with survival from cardiac arrest. The CPR technique restores and maintains the breathing and circulation of blood after cardiacarrest, preventing brain damageand mortality [5]. The CPR technique applied to the patient of cardiac rest facilitates the flow to the brain and heart till the defibrillat or becomes available. Administration of CPR technique is necessary by a professional and skilled individual during emergency cardiac events.

\section{Problem statement}

Awareness regarding the CPR technique among university students is significant as there is a lack of research related to the awareness of CPR. CPR technique has proved to increase the chance of survival from various cardiac complications; however, the awareness level of CPR in Saudi Arabia is not satisfactory. This study has assessed the knowledge about the practical skills and implication of CPR technique.

\section{Significance of the study}

CPR technique may provide the chance of survival from cardiac arrest in non-clinical environment. Most of the people are unaware about the significance of CPR technique in saving life and improving the quality of community health. Therefore, this study has examined the level of awareness about CPR technique among the university students.

\section{Aim of the study}

The early initiation of cardiopulmonary resuscitation increases the chance of survival after cardiac arrest. This study has aimed to evaluate the knowledge and awareness about cardiopulmonary resuscitation among the preparatory year students of Umm Al-Qura University.

*Corresponding Author: Dr. Ahmed Ali Shammah, Department of clinical technology, Faculty of applied medical science, EMS, Umm Al-Qura University, Makkah, Saudi Arabia; Email: ahghamdi2@yahoo.com

Citation: Shammah AA, Elbakh A, Jamal MM, Althubyani ADA, Alotaibai ZM et al. (2018) Attitudes and Awareness Towards Cardiopulmonary Resuscitation Among Preparatory Year Students of Umm Al-Qura University. Int J Community Fam Med 3: 136. https://doi.org/10.15344/2456-3498/2018/136

Copyright: (C) 2018 Shammah, et al. This is an open-access article distributed under the terms of the Creative Commons Attribution License, which permits unrestricted use, distribution, and reproduction in any medium, provided the original author and source are credited. 
Citation: Shammah AA, Elbakh A, Jamal MM, Althubyani ADA, Alotaibai ZM, et al. (2018) Attitudes and Awareness Towards Cardiopulmonary Resuscitation Among Preparatory Year Students of Umm Al-Qura University. Int J Community Fam Med 3: 136. https://doi.org/10.15344/2456-3498/2018/136

Page 2 of 4

\section{Research questions}

1. What is the level of awareness among the Umm Al-Qura university students of the preparatory year regarding the CPR technique?

2. What is the attitude of Umm Al-Qura university students about learning and implicating CPR technique?

\section{Literature Review}

CPR technique is defined as a chain of survival by American Heart Association as this technique has provided the greatest chance of survival to the patient of cardiac arrest [6,7]. It is a life saving first aid skill that is practiced across the globe. Despite the significant role played by CPR technique, the attitude towards disseminating, performing, and learning CPR in preparatory students of Umm AlQura University is not clear.

\section{Attitudes towards CPR technique}

CPR technique is widely known to be the most evolving area of modern medicine as it has proved to be a life-saving technique in emergency situations. The patients in critical condition at the time of cardiopulmonary arrest; therefore, abrupt CPR needs to be performed for successful resuscitation. Majority of the students [80\%] from King Saud University were keen to learn about the performance of CPR technique. Moreover, $45 \%$ of the students stated that the training for CPR be made a graduation requirement1.It is also necessary for school teachers to have appropriate knowledge about CPR. Among the school teachers in Riyadh, approximately $53 \%$ of the teachers believed that the training courses for CPR should be made compulsory for the students [8]. After the advancement in technology, the information about CPR is accessible through media and internet.

Globally, the teachers and students have been assessed to be willing in taking training for CPR. The technique of CPR was well received and implemented when it was introduced in the schools of United Kingdom [9]. It is sign if I can't that every individual should know about CPR to save lives to improve the quality of community health. $67 \%$ of secondary school students in Riyadh were positive about learning CPR technique [10]. Although, the knowledge about CPR technique was poor, around $73 \%$ of the surveyed individuals wanted to learn more about CPR [11].

\section{Awareness regarding CPR technique}

The survival of patient in case of cardiac arrest depends on the application of CPR technique. Awareness regarding this technique is likely to increase the survival rates of patients suffering from cardiac arrest [12]. Alanazietal [10] investigated that only $35 \%$ of students were aware about the basic training of CPR; where as, $58 \%$ students did not have any knowledge about the CPR technique. $14.7 \%$ students took training for CPR and $85.3 \%$ students never took training to learn about this technique, due to lack of awareness regarding its importance [13]. Luteal [14] recruited the university students. It has been observed that the students belonging to non-medical field were $29.9 \%$ where as $45.3 \%$ of medical university students were ready to perform CPR in $n$ emergency situation [14]. The unwillingness to perform CPR among the students of non-medical field was mainly due to fear of legal dispute sand lack of confidence. There was a positive attitude of students towards learning CPR technique. Majority of school teachers in Saudi Arabia lack the knowledge about CPR, but 75\% were willing to learn about it [9]. If teachers are well trained with basic knowledge about CPR, it is likely that they would train the students and teachers to reinforce their own knowledge.

The study conducted on the university students in Riyadh revealed that $85 \%$ of the students, who had some knowledge about CPR believed that their knowledge was not sufficient [1]. Medical students indicated low level of practical application of skills regarding CPR. This may be because the medical students are taught about CPR in later year so study. Practical applications of CPR are demonstrated during the period of house job [6].

\section{Automated external defibrillator [AED]}

Automated External Defibrillator is a portable device that facilitates the delivery of electric shock waves to the heart through chest. These shock waves have the ability to induce normal heartbeat after sudden cardiac arrest that had induced irregular heartbeats. In the case of ventricular fibrillation characterized by unsynchronized and rapid heart rate, the heart immediately needs to be defibrillated. Immediate defibrillation is necessary as the chance of survival for the affected person decreases $7-10 \%$ with each minute.

\section{Methodology}

Qualitative and quantitative approaches have been applied as a mixed research design. These methods we reused to explain different characteristics and phenomena associated with awareness regarding CPR technique. The sample comprised of 98 students selected randomly from the preparatory year of UmmAl-Qura University. The students belonged to administrative and scientific programs. Questionnaire was designed to determine the knowledge, awareness, and skills about CPR among preparatory year students. The question are include different items including, level of knowledge about CPR, level of practical skills for CPR, awareness about CPR technique.

The responses of students were processed using Statistical Package of Social sciences (SPSS) version 20.0. The frequency and percentages were calculated for evaluating quality of each item. Lowest value was indicated between 4-7, moderate value $8-11$, and high value 12-16. To calculate the dimension for discrimination items and internal structure of coefficient items, correlation coefficient was used. The validity and reliability of questionnaires were checked through Cronbach's alpha correlation, which showed are liable value of the questionnaire (Cronbach's alpha $=0.8$ ). The knowledge of CPR among students of administrative and scientific program was compared using $\mathrm{t}$-test analysis.

\section{Results}

The level of knowledge, practical skills, and importance of cardiopulmonary resuscitation has been assessed among the students of Umm Al-Qura University. The average knowledge of CPR among students of administrative and scientific program was 7.97, the average practice skills among them was 9.4 , and importance level of cardiopulmonary resuscitation was 10.6 (Table1).

The average level of knowledge about CPR among students belonging to administrative program was calculated to be 7.17 , and scientific program was 8.29 with a difference of 1.11 . It showed that there was no difference in the knowledge level about CPR among students from administrative and scientific programs (Table 2). 
Citation: Shammah AA, Elbakh A, Jamal MM, Althubyani ADA, Alotaibai ZM, et al. (2018) Attitudes and Awareness Towards Cardiopulmonary Resuscitation Among Preparatory Year Students of Umm Al-Qura University. Int J Community Fam Med 3: 136. https://doi.org/10.15344/2456-3498/2018/136

Page 3 of 4

Moreover, finding suggested that there was no difference in the average practice skill of administrative and scientific program students regarding CPR. The average practice skills among students of scientific program was 9.9 and administrative program was 8 (mean difference $=1.9$ ) (Table 2). The average importance level among students of both scientific and administrative field regarding learning of CPR was 10.5 and 10.8 respectively (Mean difference $=0.3$ ). It clearly showed that there was no difference in the importance level regarding the learning of CPR among students of both programs (Table 2).

The results depicted that the students were well aware about the importance of learning CPR, but still they want the courses to be optional even if they are free. It clearly indicated lack of awareness among the students regarding the importance of learning CPR.

\begin{tabular}{|l|c|c|c|}
\hline & Knowledge & Practice Skills & $\begin{array}{c}\text { Awareness for } \\
\text { Importance }\end{array}$ \\
\hline Items No. & 3 & 4 & 4 \\
\hline Mean & 7.97 & 9.4 & 10.6 \\
\hline $\begin{array}{l}\text { Standard } \\
\text { Deviation }\end{array}$ & 2 & 3 & 2.5 \\
\hline Median & 10 & 11 & 9.5 \\
\hline Maximum Value & 12 & 16 & 16 \\
\hline $\begin{array}{l}\text { Maximum Value } \\
\text { Frequency }\end{array}$ & 1 & 1 & 1 \\
\hline Minimum Value & 4 & 4 & 10 \\
\hline $\begin{array}{l}\text { Minimum Value } \\
\text { Frequency }\end{array}$ & 4 & 2 & 12 \\
\hline Range & 8 & 12 & 4 \\
\hline
\end{tabular}

\section{Discussion}

The study has investigated the knowledge, attitudes, level of knowledge, and practical skills regarding CPR among the students of Umm Al-Qur University, studying administrative and scientific program. It is said that CPR is one of the critical life-saving skills that every individual should know how to perform. Majority of students from King Saud University in Saudi Arabia have been investigated to realize the importance of CPR. Unfortunately, around $85 \%$ of the students felt that their knowledge regarding CPR was not adequate [11] Thus, it is identified that lack of knowledge would result in inability to perform CPR in emergency situations. A study investigated that around $31 \%$ of university students in Riyadh had no prior knowledge about the CPR technique. $85 \%$ of the students, who were previously aware about this technique, felt that their knowledge regarding this technique was not adequate. Due to lack of knowledge about CPR, only $14 \%$ of the students performed CPR in emergency situation [9].

Khader et al. [15] recruited health-college students at Taif University in Saudi Arabia. The results showed that the level of knowledge regarding CPR among the students was not satisfactory. Although, the students belonged to medical profession; they lacked theoretical and clinical training about CPR [15]. Moreover, the university medical students had adequate knowledge about the importance of CPR technique in clinical practice. However, only $20.4 \%$ of the students were well-aware for performing CPR properly [16]. Among the medical students, only $14.7 \%$ had taken CPR course; whereas, majority of the students [85.3\%] had no attended any course about CPR. 13 The attitude and skills regarding CPR was investigated to be poorer among university students. Around $50 \%$ of health science graduates knowledge towards CPR was not sufficient [17]. It occurred because of in appropriate training during under graduate course.

\begin{tabular}{|c|c|c|c|c|c|c|}
\hline & \multicolumn{3}{|c|}{ Levene's Test for Equality of Variances } & \multicolumn{3}{|c|}{ T-test for Equality of Means } \\
\hline \multicolumn{7}{|c|}{ Relationship between the Knowledge Level and the Type of Program } \\
\hline Level of Knowledge & $\mathrm{F}$ & Significance & $\mathrm{T}$ & $\mathrm{df}$ & Sig [2tailed] & Mean Difference \\
\hline \multicolumn{7}{|l|}{ Equal Variances } \\
\hline & & & -2.15 & 96 & 0.13 & 1.11 \\
\hline \multirow[t]{2}{*}{ Unequal Variances } & 1.49 & 0.23 & & & & \\
\hline & & & -2.11 & 47.63 & 0.017 & 1.11 \\
\hline \multicolumn{7}{|c|}{ Relationship between the Level of Practice Skills and the Type of Program } \\
\hline Practice Skills & $\mathrm{F}$ & Significance & $\mathrm{T}$ & df & Sig [2tailed] & Mean Difference \\
\hline \multicolumn{7}{|l|}{ Equal Variances } \\
\hline & & & -2.979 & 96 & 0.004 & -1.092 \\
\hline \multirow[t]{2}{*}{ Unequal Variances } & 0.003 & 0.954 & & & & \\
\hline & & & -3.054 & 52.54 & 0.004 & -1.928 \\
\hline \multicolumn{7}{|c|}{ Relationship between the Level of Importance and the Type of Program } \\
\hline Importance Level & $\mathrm{F}$ & Significance & $\mathrm{T}$ & df & Sig [2tailed] & Mean Difference \\
\hline \multicolumn{7}{|l|}{ Equal Variances } \\
\hline & & & 0.490 & 96 & 0.626 & 0.271 \\
\hline \multirow[t]{2}{*}{ Unequal Variances } & 0.034 & 0.854 & & & & \\
\hline & & & 0.490 & 49.66 & 0.627 & 0.271 \\
\hline
\end{tabular}

Table2: Relationship between Levels of Knowledge, PracticeSkills, Importance Level, and Type of Program. 
Citation: Shammah AA, Elbakh A, Jamal MM, Althubyani ADA, Alotaibai ZM, et al. (2018) Attitudes and Awareness Towards Cardiopulmonary Resuscitation Among Preparatory Year Students of Umm Al-Qura University. Int J Community Fam Med 3: 136. https://doi.org/10.15344/2456-3498/2018/136

Page 4 of 4

\section{Conclusion}

The overall attitude and practical skill so preparatory year students of Umm Al-Qura University were moderate. Although, the students had in adequate knowledge about CPR, but they had positive attitudes towards learning. Training about CPR is a significant factor that reinforces the students to initiate CPR. Therefore, there is a need to focus on the improve men to f CPR skills. Similarly, there is also a need to provide training for learning CPR technique among graduates. Effective training program should help in increasing knowledge and awareness of CPR among university students. Future studies are needed to assess the knowledge and attitudes towards CPR among students, specifically related with it simplification.

\section{Competing Interests}

The authors declare that no competing interests exist.

\section{References}

1. Al-Turki YA, Al-Fraih YS, Jalaly JB, Al-Maghlouth IA, Al-Rashoudi FH, et al. (2008) Knowledge and attitudes towards cardiopulmonary resuscitation among university students in Riyadh. Saudi Arabia. Saudi medical journal 29: $1306-1309$.

2. Narayan DP, Biradar SV, Reddy MT, BKS (2015) Assessment of knowledge and attitude about basic life support among dental interns and post graduate students in Bangalore city, India. World journal of emergency medicine 6: 118.

3. Sharma R, Attar NR (2012) Adult Basic life Support [BLS] awareness and knowledge among medical and dental interns completing internship from deemed university. NUJHS 2: 6-13.

4. Grunau B, Scheuermeyer FX, Stub D, Boone RH, Finkler J, et al. (2016) Potential candidates for a structured Canadian ECPR program for out-ofhospital cardiac arrest.CJEM 18: 453-460.

5. Abella BS. (2013) The importance of cardiopulmonary resuscitation quality. Current opinion noncritical care 19: 175-180.

6. Okonta KE, Okoh BA. (2015) The oretical knowledge of cardiopulmonary resuscitation among clinical medical students in the University of Port Harcourt, Nigeria. African Journal of Medical and Health Sciences 14: 42.

7. Suzuki A, Suzuki Y, Takahata O, Fujimoto K, Nagashima K, et al. (2001) A survey of 3,3036th-year medical students from 36 universities concerning knowledge of resuscitation-more than $80 \%$ of medical students cannot perform standard cardiopulmonary resuscitation?. Masui. The Japanese journal of anesthesiology 50: 316-322.

8. Alharbi MM, Horaib YF, Almutairi OM, Alsuaidan BH, Alghoraibi MS, et al. (2016) Exploring the extent of knowledge of CPR skills among school teachers in Riyadh, KSA. Journal of Taibah University Medical Sciences 11: 497-501.

9. AlEnizi BA, Saquib N, Zaghloul MSA, Alaboud MSA, Shahid MS, et al. (2016) Knowledge and Attitudes about Basic Life Support among Secondary School Teachers in Al-Qassim, Saudi Arabia. International Journal of Health Sciences 10: 415

10. Alanazi A, Hotan B, ALqahtani M, ALhalyabah H,Alanazi A, et al. (2013) Community awareness about cardiopulmonary resuscitation among secondary school students in Riyadh. World Journal of Medical Sciences 8: 186-189.

11. Larsen P, Pearson J, Galletly D (2004) Knowledge and attitudes towards cardiopulmonary resuscitation in the community. The New Zealand Medical Journal (Online) 117.

12. Weisfeldt ML (2004) Public access defibrillation: good or great?. BMJ: British Medical Journal 328: E271.

13. Roshana S, Batajoo KH, Piryani RM, Sharma MW (2012) Basic life support: knowledge and attitude of medical/paramedical professionals. World $\mathrm{J}$ Emerg Med 3: 141-145.
14. Lu C, Jin Y, Meng F, Wang Y, Shi X, et al. (2016) An exploration of attitudes toward by stander cardiopulmonary resuscitation in university students in Tianjin, China: Asurvey. International emergency nursing 24: 28-34.

15. Khader KA, Al-Ghamdi AN, Youssef HA, Elryah A, Ayasrehl RI, et al. (2016) Awareness and Knowledge of Health-College Students of Cardiopulmonary Resuscitaon at Taif University, Saudi Arabia Int J of Multidisciplinary and Current research 4

16. Kumari KM, Amberkar MB, Alur SS, Bhat PM, Bansal S, et al. (2008) Clinical awareness of do's and don'ts of cardiopulmonary resuscitation (CPR) among university medical students-A Question naire Study. Journal of clinical and diagnostic research: JCDR 8: MC08.

17. Gebremedhn EG, Gebregergs GB, Anderson BB, Nagaratnam V (2017) Attitude and skile levels of graduate health professional performing cardiopulmonary resuscitation. Advancesin Medical Education and Practice 8: 43. 